DOI https://doi.org/10.46845/2541-8254-2021-3(30)-9-9

УДК 637.1

\title{
КИСЛОМОЛОЧНЫЙ НАПИТОК, ОБОГАЩЕННЫЙ БИОЛОГИЧЕСКИ АКТИВНЫМИ ВЕЩЕСТВАМИ БИОМАССЫ ARTHROSPIRA
}

\author{
А. В. Шкловец, студентка 4-го курса, \\ e-mail: sashashklovets@mail.ru \\ ФГБОУ ВО «Калининградский государственный \\ технический университет» \\ С. В. Агафонова, канд. техн. наук, доц., \\ e-mail: svetlana.agafonova@klgtu.ru \\ ФГБОУ ВО «Калининградский государственный \\ технический университет»
}

Проведено исследование по производству йогурта, обогащенного биологически активными веществами биомассы Arthrospira (спирулины) с добавлением яблочного повидла. Также проведено маркетинговое исследование потребительских предпочтений в области кисломолочных напитков и опрос желательности потребления нового вида обогащенного йогурта. Определена оптимальная рецептура кисломолочного напитка с применением метода математического моделирования эксперимента. Представлены показатели качества и идентификации готового продукта, биологическая ценность, функциональность и рекомендации по применению обогащенного йогурта.

Ключевые слова: обогащченный йогурт, биологически активные вещества, биойогурт, биомасса Arthrospira, спирулина, биологическая иенность, функииональный продукт.

\section{ВВЕДЕНИЕ}

Молочные продукты традиционно составляют значительную часть пищевой корзины россиян. Несмотря на громкие споры о влиянии молока на организм человека и попытки оправдания безмолочной диеты, невозможно представить жизнь людей без творога, йогурта, простокваши и других подобных продуктов.

Калининградская область во все времена славилась коровами-рекордсменками, возглавляла список регионов-лидеров в производстве молока и продукции из них. Министерство сельского хозяйства области ежегодно дает сведения об увеличении надоев молока. В 2020 году прирост составил 8,5 \%, в абсолютных числах было получено около 200 тысяч тонн. Важный момент: Калининград постепенно переходит на полную независимость от поставщиков из других регионов [1].

Пищевая промышленность, в том числе и молочная, ориентирована на выпуск не просто качественной и вкусной продукции, но и на максимальную ее полезность для людей. Так появляются товары, обогащенные белком, микроэлементами, витаминами, полезной микрофлорой. Наиболее удобны для обогащения кисломолочные продукты. По статистике самые востребованные потребителями из этого ряда продуктов - кефир и йогурт с постоянным возрастанием доли последнего. За последние 5 лет (с 2013 по 2018 гг.) доля йогуртов возросла с 25,1 \% до 27,8 \% [4].

Большая перспектива в качестве ценного биотехнологического продукта имеется у цианобактерии (микроводоросли) рода Arthrospira.

Коммерческое название цианобактерий рода Arthrospira - спирулина - известно широко за пределами пищевой и фармацевтической промышленности. БАДы, содержащие 
этот продукт, очень востребованы обществом. Возможность соединения пищевой добавки с молочными продуктами позволяет создать идеально полезный перекус для людей, ведущих здоровый образ жизни. Для ослабленных пациентов, детей-малоежек полезный и вкусный продукт даст необходимые пищевые и незаменимые вещества.

Спирулина - источник легкоусвояемого белка с незаменимыми аминокислотами, полиненасыщенных жирных кислот (с высоким содержанием гамма-линоленовой кислоты), витаминов практически всех групп, минералов, других биологически активных веществ [6]. У микроорганизмов этой группы есть уникальная особенность: синий пигмент фикоцианин один из мощнейщих известный ученым антиоксидант. Именно его содержание в комплексе с хлорофиллом придает водорослям характерную окраску.

По последним данным при регулярном использовании фикоцианин оказывает благоприятное влияние на организм:

- уменьшает количество свободных радикалов, снижается окислительный стресс;

- нормализует иммунную защиту, в том числе и по отношению к злокачественным клеткам;

- стабилизирует нервную систему;

- повышает устойчивость к ионизирующему излучению;

- улучшает кровообращение, выделение токсинов с лимфатической системой;

- улучшает пищеварение за счет хорошей выработки желчных кислот [5].

Спирулина крайне позитивно влияет на основную массу молочнокислых бактерий. По исследованиям наиболее часто используемые штаммы микроорганизмов (Lactococcus lactis, Lactobacillus родов acidophilus, bulgaricus и casei, Streptococcus thermophilus) лучше растут и/или выживают в периоды ферментации во время производства и хранения готовой продукции [7].

Именно благодаря подобному синергизму препараты биомассы сине-зеленых водорослей крайне перспективны для обогащения кисломолочных продуктов, в том числе и йогуртов.

\section{ОБЪЕКТ ИССЛЕДОВАНИЯ}

Объектами исследования в нашем случае были (сырье и продукты):

- молоко с массовой долей жира 2,5\%;

- молоко сухое обезжиренное с массовой долей жира 1,5\%;

г. Москва);

- закваски для йогурта VIVO производителя ООО «ВИВО Индустрия» (Россия,

- спирулина в виде сухой готовой биомассы производителя Ритмико Биотех (Россия, г. Екатеринбург);

- повидло яблочное «Летнее», производителя ООО «Первый Георгиевский консервный завод» (Россия);

- контрольные образцы йогуртов без обогатителей с массовой долей жира 2,4 \%;

- йогурт, обогащенный спирулиной и яблочным повидлом, с массовой долей жира 2,4 \%.

Таблица 1 - Состав заквасок для йогурта VIVO

\begin{tabular}{|c|c|}
\hline Наименование закваски & Состав \\
\hline «Бифивит» & $\begin{array}{l}\text { Bifidobacterium lactis (2 штамма), Bifidobacterium infantis, Streptococcus } \\
\text { thermophilus, Lactobacillus bulgaricus, Lactobacillus paracasei, } \\
\text { Lactobacillus acidophilus ( } 2 \text { штаммa) }\end{array}$ \\
\hline «Fit» & $\begin{array}{l}\text { Streptococcus thermophilus, Bifidobacterium lactis, Lactobacillus } \\
\text { delbrueckii ssp.bulgaricus, Lactobacillus gasseri Lactobacillus acidophilus }\end{array}$ \\
\hline «Йогурт» & $\begin{array}{l}\text { Streptococcus thermophilus, Bifidobacterium lactis Lactobacillus delbrueckit } \\
\text { ssp.bulgaricus, Lactobacillus acidophilus }\end{array}$ \\
\hline
\end{tabular}




\section{ЦЕЛЬ И ЗАДАЧИ ИССЛЕДОВАНИЯ}

Была поставлена цель исследования: разработка и оценка показателей качества биойогурта обогащенного биологически активными веществами биомассы Arthrospira (спирулина) с добавлением яблочного повидла.

Задачи:

1. Подтвердить актуальность и необходимость продукта. Для этого провели стандартные маркетинговые исследования, был проанализирован сегмент кисломолочной продукции, особенно актуальный для Калининградской области.

2. Выбрать оптимальную закваску для йогурта, обосновать это экспериментально.

3. Разработать рецептуру обогащенного йогурта.

4. Определить пищевую ценность и функциональность обогащенного йогурта.

5. Дать рекомендации по потреблению обогащенного йогурта.

Экспериментальные исследования проводились в лаборатории кафедры пищевой биотехнологии ФГБОУ ВО «КГТУ».

\section{МЕТОДЫ ИССЛЕДОВАНИЯ}

Полученный йогурт был исследован стандартными методами, в которые входили как субъективные органолептические, так и объективные физико-химические.

Для определения органолептических параметров использовали расширенную пятиуровневую шкалу, где максимальные 9 баллов соответствовали оценке «отлично»; определению «хорошо» отвечали 7 баллов; критерию «менее привлекательно» присваивали 5 баллов; далее - «удовлетворительно» - 3 и «плохо» - 1. Подобная градация позволила полностью оценить цвет, консистенцию, запах и вкус готового продукта [3].

Титруемую кислотность сырья (молоко) и опытных образцов йогуртов определяли по ГОСТ Р 54669-2011. Метод основан на нейтрализации кислот, содержащихся в продукте, раствором гидроокиси натрия в присутствии индикатора фенолфталеина.

Массовую долю сухих веществ в молоке и полученных образцах йогуртов определяли методом высушивания навески до постоянной массы при $100-105{ }^{\circ} \mathrm{C}$.

Массовую долю золы в спирулине определяли по ГОСТ 33331. Метод основан на удалении органических веществ из навески продукции сжиганием и определении массы золы взвешиванием.

Содержание $\boldsymbol{\beta}$-каротина в пищевом обогатителе - спирулине. Метод основан на изменении интенсивности светопоглощения растворов $\beta$-каротина, который экстрагировали органическим растворителем и измеряли поглощение его растворов на спектрофотометре при 460 нм.

Планирование экспериментов при моделировании и оптимизации рецептуры обогащенных йогуртов осуществляли согласно ортогонального планирования второго порядка для двух факторов.

Таблица 2 - Изменяемые факторы (дозировки спирулины и яблочного повидла), их интервалы и предельные значения

\begin{tabular}{|c|c|c|c|c|}
\hline \multirow{2}{*}{ Факторы } & \multicolumn{3}{|c|}{ Уровни } & \multirow{2}{*}{$\begin{array}{c}\text { Интервал } \\
\text { варьирования }\end{array}$} \\
\hline & -1 & 0 & +1 & \\
\hline $\begin{array}{l}\text { Количество } \\
\text { спирулины, } X_{1}, \Gamma\end{array}$ & 1 & 1,75 & 2,5 & 0,75 \\
\hline $\begin{array}{l}\text { Количество } \\
\text { яблочного повидла, } \mathrm{X}_{2}, \Gamma\end{array}$ & 7 & 10 & 13 & 3 \\
\hline
\end{tabular}


Таблица 3 - План эксперимента и результаты реализации при планировании рецептуры обогащенного йогурта

\begin{tabular}{|c|c|c|c|c|}
\hline \multirow{2}{*}{$№$} & \multicolumn{2}{|c|}{ План эксперимента } & \multirow{2}{*}{$\begin{array}{c}\text { Частный отклик- } \\
\text { органолептическая оценка, балл }\end{array}$} & $\begin{array}{c}\text { Параметр } \\
\text { оптимизации }\end{array}$ \\
\hline 1 & $\mathrm{X}_{1}$ & $\mathrm{X}_{2}$ & 7 & 0,049 \\
\hline 2 & 2,5 & 13 & 8 & 0,012 \\
\hline 3 & 1 & 13 & 6 & 0,111 \\
\hline 4 & 2,5 & 10 & 8,5 & 0,003 \\
\hline 5 & 2,5 & 10 & 7 & 0,049 \\
\hline 6 & 1 & 7 & 9 & 0 \\
\hline 7 & 1,75 & 7 & 8 & 0,012 \\
\hline 8 & 1,75 & 10 & 8 & 0,012 \\
\hline 9 & 1,75 & 13 & 8 & 0,012 \\
\hline
\end{tabular}

Анализ данных табл. 3 показал, что оптимальным является соотношение спирулины 1 г и яблочного повидла - 7 г (опыт № 6). Этот образец набрал наибольший балл с минимальным обобщенным параметром оптимизации. На втором месте был вариант под № 4. Частный отклик на него близок к идеальному, отличаясь всего на 0,5 баллов с параметром оптимизации - 0,003.

В результате вычисления коэффициентов математической регрессии была получена кодированная математическая модель рецептуры. Далее был произведен переход к натуральной модели рецептуры обогащенного йогурта, которая дает возможность прогнозировать качество готового продукта (1):

$$
Y=0,04 \tilde{x}_{1}^{2}-0,008 \tilde{x}_{1} \tilde{x}_{2}+0,0014 \tilde{x}_{2}^{2}-0,028 \tilde{x}_{1}-0,017 \tilde{x}_{2}+0,099,
$$

где у - параметр оптимизации;

$\tilde{x}_{1}-$ содержание спирулины, г; $\tilde{x}_{2}$ - содержание яблочного повидла, г.

Модель дает возможность рассчитать оптимальные значения вносимых компонентов в рецептуре обогащенного йогурта через дифференцирование натуральных моделей (2), (3):

$$
\begin{aligned}
& \frac{d y}{d x_{1}}=0,08 \tilde{x}_{1}-0,008 \tilde{x}_{2}-0,028, \\
& \frac{d y}{d x_{2}}=0,028 \tilde{x}_{2}-0,008 \tilde{x}_{1}-0,017 .
\end{aligned}
$$

Расчетные оптимальные значения компонентов (на 150 г продукта):

- содержание спирулины $\tilde{x}_{1}=1,34$ г;

- содержание яблочного повидла $\tilde{x}_{2}=9,9$ г.

На основании полученных данных и их математической обработки выстроена геометрическая модель рецептуры обогащенного йогурта (рис. 3). 


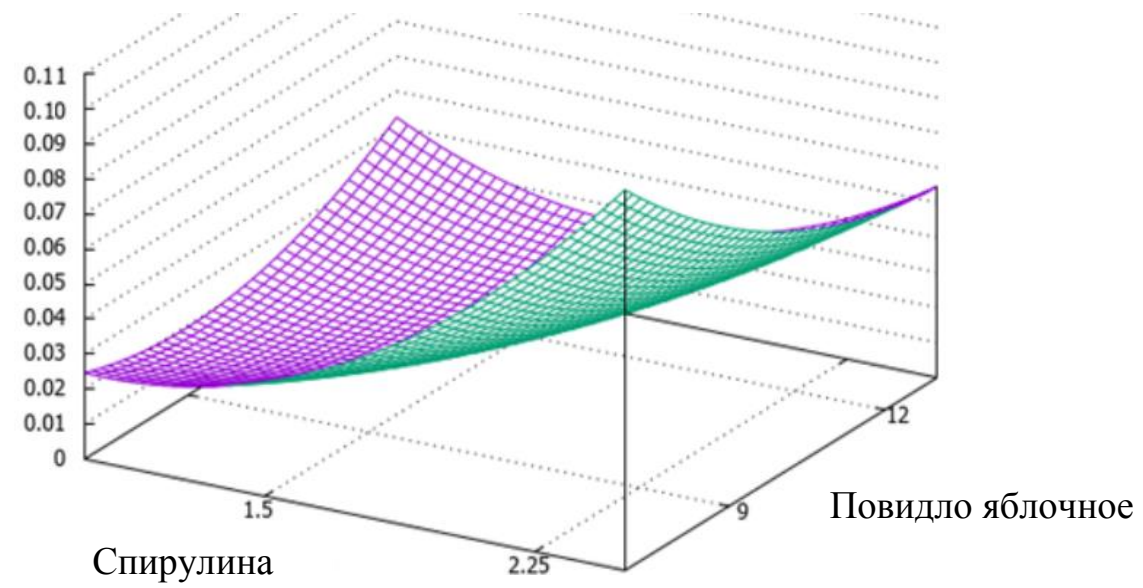

Рисунок 3 - Геометрическая структура модели рецептуры обогащенного йогурта

\section{Выбор закваски}

Проводилась оценка трех видов заквасок одного производителя: VIVO «Fit», VIVO «Бифивит», VIVO «Йогурт». Оценивались скорость сквашивания молока (время, за которое кислотность сгустка достигала 75-80 ${ }^{\circ} \mathrm{T}$ ) и органолептические показатели качества выработанных йогуртов.

Таблица 4 - Органолептические и физико-химические характеристики йогуртов, выработанных термостатным способом $\left(\mathrm{t}=40,0^{\circ} \mathrm{C}\right)$

\begin{tabular}{|c|c|c|c|}
\hline $\begin{array}{c}\text { Наименование } \\
\text { показателя }\end{array}$ & $\begin{array}{c}\text { Биойогурт с закваской } \\
\text { VIVO «Fit» }\end{array}$ & $\begin{array}{c}\text { Биойогурт с } \\
\text { закваской VIVO } \\
\text { «Бифивит» }\end{array}$ & $\begin{array}{c}\text { Биойогурт с закваской } \\
\text { VIVO «Йогурт» }\end{array}$ \\
\hline $\begin{array}{l}\text { Внешний вид } \\
\text { и консистенция }\end{array}$ & $\begin{array}{l}\text { Однородная масса, } \\
\text { сгусток цельный } \\
\text { ненарушенный. } \\
\text { Вязкость умеренная, } \\
\text { количество отделившейся } \\
\text { сыворотки } \\
\text { незначительное }\end{array}$ & $\begin{array}{l}\text { Йогурт однородный, } \\
\text { с цельным сгустком, } \\
\text { вязкий }\end{array}$ & $\begin{array}{lr}\text { Структура однородная, } \\
\text { ненарушеннй } \\
\text { в меру вязкая }\end{array}$ \\
\hline Вкус и запах & Чистый, молочный & $\begin{array}{l}\text { Чистый, } \\
\text { молочный }\end{array}$ & $\begin{array}{l}\text { Чистый, } \\
\text { молочный, сладковатый- }\end{array}$ \\
\hline Цвет & Молочно-белый & Молочно-белый & Молочно-белый \\
\hline $\begin{array}{l}\text { Кислотность, }{ }^{\circ} \mathrm{T}: \\
-\quad \text { через } 5 \text { ч }\end{array}$ & (1) & 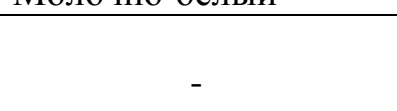 & $82^{\circ} \mathrm{T}$ \\
\hline $\begin{array}{l}\text { сквашивания } \\
-\quad \text { через } 6 \quad \text { ч } \\
\text { сквашивания }\end{array}$ & $28^{\circ} \mathrm{T}$ & $52^{\circ} \mathrm{T}$ & $95^{\circ} \mathrm{T}$ \\
\hline $\begin{array}{l}-\quad \text { через } 7 \text { ч } \\
\text { сквашивания }\end{array}$ & $35^{\circ} \mathrm{T}$ & $69^{\circ} \mathrm{T}$ & $103^{\circ} \mathrm{T}$ \\
\hline $\begin{array}{l}-\quad \text { через } 8 \text { ч } \\
\text { сквашивания }\end{array}$ & $50^{\circ} \mathrm{T}$ & $93^{\circ} \mathrm{T}$ & - \\
\hline $\begin{array}{l}-\quad \text { через } 9 \text { ч } \\
\text { сквашивания }\end{array}$ & $66^{\circ} \mathrm{T}$ & - & - \\
\hline $\begin{array}{l}-\quad \text { через } 10 \text { ч } \\
\text { сквашивания }\end{array}$ & $85^{\circ} \mathrm{T}$ & - & - \\
\hline
\end{tabular}

По результатам органолептической и физико-химической оценки йогуртов наилучшими показателями обладала закваска VIVO «Йогурт».

Исходя из полученных опытным путем данных, разработана рецептура йогурта, обогащенного биологически активными веществами биомассы Arthrospira с добавлением яблочного повидла (табл. 5). 
Основными компонентами (молочной основой) для производства йогурта питьевого с м.Д.ж. 2,4 послужило коровье молоко с м.д.ж. 2,5 \%, молоко сухое обезжиренное с м.д.ж. 1,5 \% для нормализации молока по сухим веществам.

Таблица 5 - Рецептура йогурта, обогащенного спирулиной и яблочным повидлом

\begin{tabular}{|l|c|}
\hline \multicolumn{1}{|c|}{ Наименование ингредиента } & Количество в 100 г, \% \\
\hline Молоко цельное коровье, с м.д.ж. 2,5\% & 89,9 \\
\hline Молоко сухое обезжиренное, с м.д.ж. $1,5 \%$ & 2,8 \\
\hline Закваска VIVО «Йогурт» & 0,5 \\
\hline Повидло яблочное «Летнее» & 6,2 \\
\hline Спирулина, сухая биомасса & 0,6 \\
\hline
\end{tabular}

Пищевая ценность обогащенного йогурта была определена комбинированным экспериментально-расчетным путем и представлена в табл. 6.

Таблица 6 - Пищевая ценность обогащенного йогурта

\begin{tabular}{|l|c|c|}
\hline \multicolumn{1}{|c|}{ Наименование показателя } & На 100 г продукта & $\begin{array}{c}\text { \% удовлетворения от суточной } \\
\text { потребности }\end{array}$ \\
\hline Белки & 5,68 г & 3,68 \\
\hline Углеводы & 14,47 г & 5,0 \\
\hline Пищевые волокна & 0,46 г & 1,84 \\
\hline Кальций & $193 \mathrm{мг}$ & $\mathbf{1 9 , 5}$ \\
\hline Фосфор & $162 \mathrm{M \Gamma}$ & $\mathbf{2 3 , 2}$ \\
\hline Калий & $276,5 \mathrm{мг}$ & 5,8 \\
\hline Железо & $0,29 \mathrm{M \Gamma}$ & 2,9 \\
\hline Мель & $0,061 \mathrm{мг}$ & 6,1 \\
\hline Хлорофилл & $10 \mathrm{мг}$ & 10 \\
\hline Фикоцианин & $50 \mathrm{мг}$ & $\mathbf{1 0 0}$ \\
\hline В-каротин & $0,22 \mathrm{M \Gamma}$ & 4,46 \\
\hline Витамин В1 (тиамин) & 0,07 мг & 6,3 \\
\hline Витамин В2 (рибофлавин) & $0,24 \mathrm{мг}$ & $\mathbf{2 0 , 2 9}$ \\
\hline
\end{tabular}

При анализе таблицы мы видим, что наш продукт соответствует параметрам функциональности: по содержанию кальция - 19,5 \%, фосфора - 23,2 \%, витамина В2 (рибофлавина) - 20,3 \% от суточной нормы. По фикоцианину 100 г йогурта полностью покрывает дневную потребность человека [2].

\section{повидлом»}

Характеристика готового продукта «Биойогурт с спирулиной и яблочным

Йогурт был произведен в соответствии с необходимыми требованиями и полностью удовлетворяет ГОСТ 31981-2013. Эти данные указаны в табл. 7.

Таблица 7 - Основные органолептические свойства обогащенного йогурта

\begin{tabular}{|l|l|}
\hline \multicolumn{1}{|c|}{$\begin{array}{c}\text { Наименование } \\
\text { показателя }\end{array}$} & \multicolumn{1}{|c|}{ Характеристика } \\
\hline $\begin{array}{l}\text { Внешний вид } \\
\text { и консистенция }\end{array}$ & $\begin{array}{l}\text { Однородная, с нарушенным сгустком, в меру вязкая. } \\
\text { Имеются нерастворимые мелкие включения частиц спирулины }\end{array}$ \\
\hline Вкус и запах & $\begin{array}{l}\text { Характерный кисло-молочный запах с ароматом спирулины. } \\
\text { В меру сладкий, с соответствующим вкусом внесенных компонентов }\end{array}$ \\
\hline Цвет & $\begin{array}{l}\text { Молочно-зеленый за счет внесенных компонентов, с вкраплениями } \\
\text { нерастворимых частиц спирулины }\end{array}$ \\
\hline
\end{tabular}

Главные физико-химические показатели полученного продукта приведены в табл. 8. 
Таблица 8 - Физико-химические показатели обогащенного йогурта

\begin{tabular}{|l|c|}
\hline \multicolumn{1}{|c|}{ Наименование показателя } & Значение показателя \\
\hline Массовая доля жира, \% & 2,4 \\
\hline Массовая доля сухого обезжиренного молочного остатка (СОМО), \% & 13 \\
\hline Кислотность, ${ }^{\circ} \mathrm{T}$ & 120 \\
\hline Температура продуктов при выпуске с предприятия, ${ }^{\circ} \mathrm{C}$ & $4 \pm 2$ \\
\hline Массовая доля пищевых волокон, \% & 0,3 \\
\hline Массовая доля хлорофилла, \% & 0,007 \\
\hline Массовая доля фикоцианина, \% & 0,033 \\
\hline
\end{tabular}

\section{Рекомендации по применению}

Йогурт, обогащенный биологически активными веществами биомассы Arthrospira содержит достаточное количество полноценного легкоусвояемого белка, пищевые волокна, железо, медь, витамины группы В. Из других важных компонентов особого внимания заслуживают хлорофилл, содержание которого обеспечивает суточную потребность в нем на $10 \%$ и фикоцианин - $100 \%$ от необходимой ежедневной нормы.

Биойогурт со спирулиной рекомендован всем группам населения для:

- повышения сопротивляемости организма сезонным вирусным инфекциями, уменьшения частоты и тяжести обострений хронических заболеваний респираторной системы;

- нормализации функции иммунитета, уменьшения окислительного стресса благодаря снижению количества свободных радикалов;

- в качестве адаптогена при активных физических, психологических нагрузках;

- улучшения пищеварения и создания условий для роста собственной полезной микрофлоры кишечника;

- пожилым людям для улучшения процессов метаболизма, прилива энергии и сил, минимизации содержания холестерина в крови и нормализации артериального давления;

- помощи при лечении анемии и недоедания у детей и пациентов с различными заболеваниями.

Рекомендуемая доза употребления продукта - 150-200 г.

\section{ЗАКЛЮЧЕНИЕ}

Важная задача пищевой биотехнологии - разработка функциональных продуктов для профилактического питания. Обогащенный спирулиной йогурт с добавлением яблочного повидла соответствует всем стандартам функциональности. Сто грамм продукта содержат 19,5 \% суточной дозы кальция, 23,2 \% фосфора, 20, 3\% витамина В2 (рибофлавина), $100 \%$ фикоцианина По требованиям ГОСТ Р 54059-2010 необходимо достичь как минимум 15 \% от ежедневной нормы.

1. Предложена рецептура обогащенного продукта. Основной профилактический ингредиент - спирулина. Яблочное повидло придает нужные органолептические свойства. Молочная основа состоит из коровьего молока с м.д.ж. 2,5 \%, молока сухого обезжиренного с м.д.ж. 1,5 \% для нормализации молока по сухим веществам.

2. Для получения необходимой кислотности и плотности сгустка в соответствии с техническими характеристиками выбрана и обоснована наиболее подходящая закваска.

3. Получена математическая модель рецептуры обогащенного йогурта и рассчитаны оптимальные значения дозировок спирулины $(\mathrm{Mc}=1,34$ г/150 г) и яблочного повидла $(\mathrm{Mя}=9,9$ г/150 г).

4. Рассчитана биологическая ценность и уровень функциональности йогурта, обогащенного спирулиной с добавлением яблочного повидла. Определена функциональность данного продукта по содержанию кальция, фосфора, рибофлавина и фикоцианина. 
5. Разработаны рекомендации по приоритетным группам потребления. В них включены люди с повышенной потребностью в белке. Это: дети; спортсмены, как профессионалы, так и любители; пожилые люди, для которых натуральное сбалансированное питание позволяет сохранять жизненную активность, поддерживать хороший объем и качество костной ткани. Продукт очень полезен тем, чьи профессии сопряжены с повышенной физической и психологической нагрузкой.

\title{
СПИСОК ЛИТЕРАТУРЫ
}

1. В регионе выросло производство молока, мяса, увеличилась самообеспеченность овощами [Электронный ресурс] // Правительство Калининградской области. URL: https://gov39.ru/press/226642/ (дата обращения: 16.04.2021)

2. $\quad$ ГОСТ Р 54059-2010 Продукты пищевые функциональные. Ингредиенты пищевые функциональные. Классификация и общие требования [Текст]. -2012-01-01. Москва: Стандартинформ, 2019.

3. Олефирова, А. П. Идентификация пищевых продуктов (органолептическая оценка) при обязательной сертификации. Метод. указания к лаб. раб. по дисциплине «Сертификация пищевых продуктов» / А. П. Олефирова [и др]. - Улан-Уде: ВСГУТУ, 2002.

4. О производстве кисломолочных продуктов в России в 2018-2019 гг. [Электронный pecypc] // Экспертно-аналитический центр агробизнеса. URL: https://abcentre.ru/news/o-proizvodstve-kislomolochnyh-produktov-v-rossii-v-2018-2019-gg (дата обращения: 10.10.2020)

5. Лукин, А. А. Научные основы производства продуктов питания с адаптогенными и стрессопротекторными свойствами / А. А. Лукин // Наука ЮУрГУ: материалы 68-й научной конференции. - С. 488-494.

6. Первушкин, С. В. Биомасса спирулины: исследования и перспективы использования: монография / С. В. Первушкин, А. В. Воронин, А. А. Сохина. - Самара: СамГМУ, 2004. - 100 с.

7. Финамор, А. Антиоксидантная, иммуномодулирующая и микробномодулирующая деятельность устойчивой и экологически чистой спирулины // Zhejiang Binmei Biotecnología Co., Ltd. URL: http://ru.binmeibio-es.com/info/antioxidantimmunomodulating-and-microbial-m-23268539.html (дата обращения 10.10.2020)

\section{SOUR MILK DRINK ENRICHED WITH BIOLOGICALLY ACTIVE SUBSTANCES OF ARTHROSPIRA BIOMASS}

\author{
A. V. Shklovets, student, \\ e-mail: sashashklovets@mail.ru \\ Kaliningrad State Technical University \\ S. V. Agafonova, PhD, Associate Professor, \\ e-mail: svetlana.agafonova@klgtu.ru \\ Kaliningrad State Technical University
}

A research was carried out on the production of yoghurt enriched with biologically active substances of Arthrospira biomass (spirulina) with the addition of apple jam. In addition, a marketing study of consumer preferences in the field of fermented milk drinks and a survey of the desirability of consuming a new type of fortified yogurt were conducted. The optimal formulation of a fermented milk drink using the method of mathematical modeling of the experiment, indicators of quality and identification of the finished product, its biological value, functionality and recommendations for the use of enriched yoghurt have been determined. 
Key words: enriched yogurt, biologically active substances, bioyogurt, Arthrospira biomass, spirulina, biological value, functional product. 